\title{
Study on modified phenolic foam for Insulation of building's exterior wall
}

\author{
Guo-zhong LU ${ }^{1, a,{ }^{*}}$, Xiao-nong $\mathrm{CHEN}^{2, \mathrm{~b}}$, Li-juan $\mathrm{ZHOU}^{1, \mathrm{c}}$, Xiu-juan DING ${ }^{3, \mathrm{~d}}$, and \\ Jin-Tai HE ${ }^{1, e}$ \\ ${ }^{1}$ Beijing Building Materials Academy of Sciences Research, Beijing 100041, P. R. China \\ ${ }^{2}$ Beijing University of Chemical Technology, Beijing 100029, P. R. China \\ ${ }^{3}$ Northeastern University at Qinhuangdao,Qinhuangdao, Hebei, China, 066004,P. R. China \\ aluguozhong@163.com, bdingxiujuanlove@126.com \\ ${ }^{*}$ Corresponding author
}

Keywords:Insulation of building's exterior wall, Phenolic foam, Modified, Heat resistance, Toughness.

Abstract. Adding nano montmorillonite and polyethylene glycol to modify phenolic resin in interlayer polymerization process to improve the heat resistance and toughness of the foam material. And the affect of phenolic ratio on the microstructure of phenolic foam was studied .Then the structure of modified phenolic resin was analyzed by the XRD tester, infrared spectroscopy and SEM. The results showed that polyethylene glycol and phenolic resin occured a strong interaction to forme the composite material, which enhanced the modified phenolic resin foam material toughness. Montmorillonite improved the heat resistance by increased distance between the phenolic resin layer to make the thermal decomposition temperature becoming $361{ }^{\circ} \mathrm{C}$. The greater the ratio of phenolic resin is, the lower reactivity of acid curing and the smaller diameter of bubbles forming will be.

\section{Introduction}

The phenolic foam is made in the method of chemical foaming by phenolic resin, known as the "King of insulation", with perfect performance in heat insulation, stability, corrosion resistance, anti-aging, little dimensional change rate, sound absorption, fire-retardant. In terms of building wall insulation materials, a variety of foams are widely used as building insulation materials, such as PVC, Polystyrene and Polyurethane foam. But most of them have poor heat resistance, and there would be flammable, toxic smoke generated and other shortcomings, hidden trouble in safety. However the combustion performance of phenolic foam insulation board is level B1, and when encounteres fire or the fire source, it will incandesce or smolder above $400{ }^{\circ} \mathrm{C}$, no flame and almost all become into char due to its uninflammability. The phenolic foam insulation board with $25 \mathrm{~mm}$ thick is sprayed by flame withstand $1700{ }^{\circ} \mathrm{C}$ for 10 minutes, the surface will be only a slight charring burn rather than burn through, which can effectively prevent fire spread. In addition, the majority of casualties are due to smoke and toxic gases in fire accidents, and even phenolic foam is ignited, there is no dripping when it burnes, smoke volume is extremely low, and almost no toxic gases . Therefore, the use of phenolic foam as exterior wall external insulation material is more energy-saving and safe. However, the low elongation, poor extensibility and cannot resist bending limites its applications, so it is necessary to toughening. In this work, it aimed to obtain both insulation and fire protection phenolic foam insulation board by modify phenolic resin.

\section{Experiment}

\section{Materials and equipment}

Materials.Nano-montmorillonite(MMT), polyethylene glycol(PEG, molecular weight is 400), phenolic resin(PF), surfactant(tween-80), foaming agent(cyclopentane), curing agent(p-toluene 
sulphonic acid and sulfate), toughening agent(SBR latex), catalyst(MgO), filler(Urea and melamine),etc.

Equipment.XRD(DIFFRACTOMETER-6000, made in Japan, Shimadzu Corporation), Infrared spectroscopy(FTIR-650, Beijing Keyi Hengda Technology Co., Ltd.), DSC analyzer(DSC0901, Hunan Zhenhua Analysis Instrument Co., Ltd.), NMR(mq-one, BRUKER Corporation), SEM(JSM-6480+INCA-EBSD+EDS, Japanese electronics),etc.

\section{Testing method}

Added mass fraction of nano montmorillonite and PEG from $1 \%$ to $5 \%$ respectively to make PF foam board,and then performance test was carried out . Preparation process was as follow. First, added mass fraction of surfactant from $3 \%$ to $4 \%$, foaming agent from $7 \%$ to $9 \%$, toughening agent from $2 \%$ to $3 \%$ and filler from $10 \%$ to $25 \%$ into phenolic resin to prepare mixed resin(Material A).Second, mixing the organic acid (p-toluenesulfonic acid) and an inorganic acid (sulfuric acid) of 1 to 3 , an acid curing catalyst was prepared (Material B). Last, different thickness of foam sheet was produced by high-speed mixing with Material A and Material B according to a certain proportion of 6 or 9 to 1, then spraying foam sheet on the production line, heating and foaming.

\section{Results and discussion}

\section{The properties of modified phenolic foam}

The oxygen index of unmodified phenolic foam was 32. Table 1 showed that the oxygen index of PF foam rose after modification.

Table 1 The properties of modified phenolic foam

\begin{tabular}{cc}
\hline Test items & Properties \\
\hline apparent density $/\left(\mathrm{kg} \cdot \mathrm{m}^{-3}\right)$ & $55 \sim 70$ \\
heat conductivity $/\left[\mathrm{W} \cdot(\mathrm{m} \cdot \mathrm{K})^{-1}\right]$ & $0.027 \sim 0.034$ \\
Tensile strength $($ direction perpendicular to the & $0.09 \sim 0.12$ \\
plate surface $/ \mathrm{MPa}$ & $>150$ \\
compressive strength $/ \mathrm{kPa}$ & $38 \sim 42$ \\
oxygen index & $5 \sim 7$ \\
water absorption, $\%$ &
\end{tabular}

Note: There lists different performance ranges according to the recipe.

Table 2 showed that there was no burning litter after unmodified phenolic foam(sample 1) burning, paper did not ignite but bombing. Burning completely and the average flue gas temperature exceed regular standard of $200{ }^{\circ} \mathrm{C}$, did not meet the requirements of the $\mathrm{B} 1$ level of combustion performance. Sample 2, after the combustion furnace test, flame arrow did not reach the mark, no burning litter, both the average residual length and the average flue gas temperature reached the standard, with a low smoke density grade, met the standard completely. 
Table 2 The performance comparison between before and after modified PF insulation board

\begin{tabular}{|c|c|c|c|}
\hline Standard & Sample 1 & Sample 2 & $\begin{array}{c}\text { Test } \\
\text { Standard }\end{array}$ \\
\hline $\begin{array}{l}\text { Flame arrow does not reach } \\
\text { the mark, and does not allow } \\
\text { the burning litter ignited } \\
\text { paper }\end{array}$ & $\begin{array}{l}\text { Flame arrow reaches } \\
\text { the mark, no burning } \\
\text { litter, paper does not } \\
\text { ignite }\end{array}$ & $\begin{array}{l}\text { Flame arrow does } \\
\text { not reach the mark, } \\
\text { no burning, paper } \\
\text { does not ignite } \\
\text { The average }\end{array}$ & \\
\hline $\begin{array}{l}\text { The average residual } \\
\text { length } \geq 15 \mathrm{~cm} \text { ( residual length } \\
\text { at any time }>0 \text { ) }\end{array}$ & $\begin{array}{l}\text { The average residual } \\
\text { length is } 0\end{array}$ & $\begin{array}{l}\text { residual length is } \\
63 \mathrm{~cm} \text {; the } \\
\text { minimum residual } \\
\text { length is } 61 \mathrm{~cm}\end{array}$ & $\begin{array}{c}\text { GB } \\
8624-2012\end{array}$ \\
\hline $\begin{array}{l}\text { the average flue gas } \\
\text { temperature } \leq 200{ }^{\circ} \mathrm{C}\end{array}$ & More than $200.0{ }^{\circ} \mathrm{C}$ & $123.1{ }^{\circ} \mathrm{C}$ & \\
\hline smoke density grade $\leq 75$ & 2.5 & 1.1 & \\
\hline
\end{tabular}

\section{Montmorillonite impact on the performance of PF}

As shown in Fig.1, the first-order diffraction peak of nano montmorillonite (MMT) was at $2 \theta=7.104^{\circ}$. According to the Bragg equation, $2 \mathrm{~d} \sin \theta=\mathrm{n} \lambda$ (In this equation, $\mathrm{d}$ is spacing of layers (nm); $\theta$ is diffraction angle; $\lambda$ is $\mathrm{x}$-ray wavelength, $\lambda=0.15406 \mathrm{~nm} ; \mathrm{n}$ is diffraction series), we could obtain the spacing of layers (d) was $1.24 \mathrm{~nm}$. However, the first-order diffraction peak of modified phenolic foam was at $2 \theta=5.378^{\circ}$, and the $2 \theta$ decrease indicated the layer spacing of MMT increase, the layer spacing of nano montmorillonite has been changed to $1.64 \mathrm{~nm}$. The layer spacing increase between MMT not only improved the thermal stability of the PF, but also played a thermal insulation, fire-retardant and enhanced role to some extent.

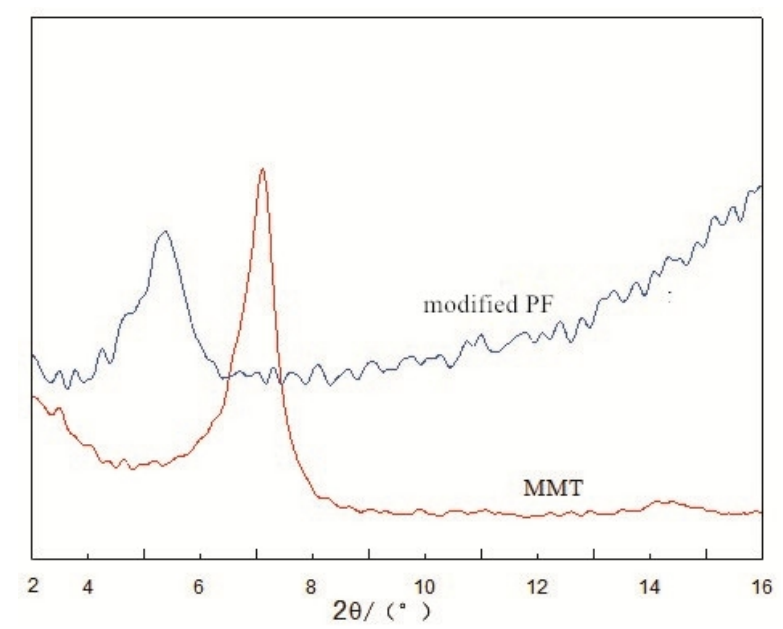

Fig.1 The X-ray diffraction of MMT and modified PF

Table 3 showed that around $800{ }^{\circ} \mathrm{C}$, the residual ratio of modified PF was $61.4 \%$ and $63.9 \%$; the thermal decomposition temperature of unmodified PF was $348{ }^{\circ} \mathrm{C}$, lower than $361{ }^{\circ} \mathrm{C}$. It indicated MMT had improved the heat resistance of PF. 
Table 3 The heat resistance of modified PF and unmodified PF

\begin{tabular}{cccc}
\hline Test items & $\begin{array}{c}\text { Initial decomposition } \\
\text { temperature } /{ }^{\circ} \mathrm{C}\end{array}$ & \multicolumn{2}{c}{ Residual rate, \% } \\
& $0 \sim 400{ }^{\circ} \mathrm{C}$ & $800{ }^{\circ} \mathrm{C}$ \\
\hline PF & 348 & 88.9 & 61.4 \\
PF modified by MMT & 361 & 90.5 & 63.9 \\
\hline
\end{tabular}

\section{The toughening mechanism of PEG to PF}

PEG could form hydrogen bonds with the phenolic hydroxyl group, while the methylene may produce a hydrophobic interaction with benzene ring of phenol structures, therefore the PEG and PF molecular chain would form molecular complexes, improving toughness of PF. As shown in Fig.2a, it was found that the wavenumbers at $3370 \sim 3380 \mathrm{~cm}^{-1}$ showed characteristic peak of phenolic hydroxyl group, and the wavenumbers at $1600 \mathrm{~cm}^{-1}$ showed characteristic peak of benzene ring; the characteristic peak of hydroxy appeared at $3340 \mathrm{~cm}^{-1}$; methylene appeared at $2880 \mathrm{~cm}^{-1}$; ether bond appeared at $1100 \mathrm{~cm}^{-1}$.

The spectral line2 in the Fig.2b was the difference of PEG and PEG-modified PF. Compared the phenolic hydroxyl spectral peak with PF spectral line(the red line in Fig.2b), characteristics of phenolic hydroxyl peak became blue shift, characteristic peaks moved to the short length direction, which showed that a strong interaction between PEG and PF occured.So it was not a simple mix between PEG and PF, but the formation of complexes, which was a strong evidence of PEG molecules on PF toughening.
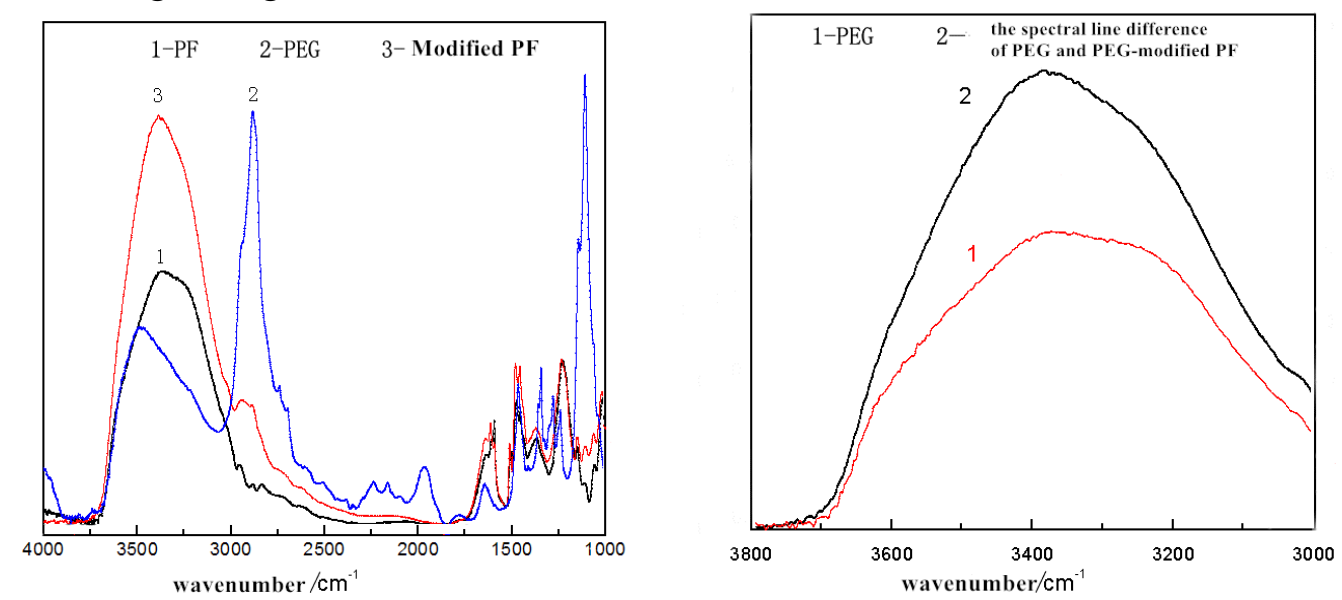

Fig.2 The IR spectra of PF, PEG and modified PF

It was found that the PF foam cell walls existed three kinds of structures, as shown in Fig.3. The pinhole was formed because that water droplet attached to pore wall was supposed to precipitate on the pore walls during a resin curing process, the position occupied was filled by resin instead of water droplet. But its water solubility and fluidity become worse and worse because of fast curing speed of resin. There was no resin to fill the hole left after the water evaporates, so it would form pinhole.The forming reasons of cracks was that during a resin curing process, slow crossing and curing speed led to the strength of pore wall not high. On the other hand, high heat output caused high internal gas pressure, and expanded continuously, pore walls were thinner until rupture finally.

Fig.3c was the complete shape of borehole wall, the formation of pore closed structure due to moderate curing rate, smooth heat output. The position was filled by resin after water droplet precipitating and eliminated pinhole. Meanwhile, the strength of pore wall reached some strength to prevent cracks. 

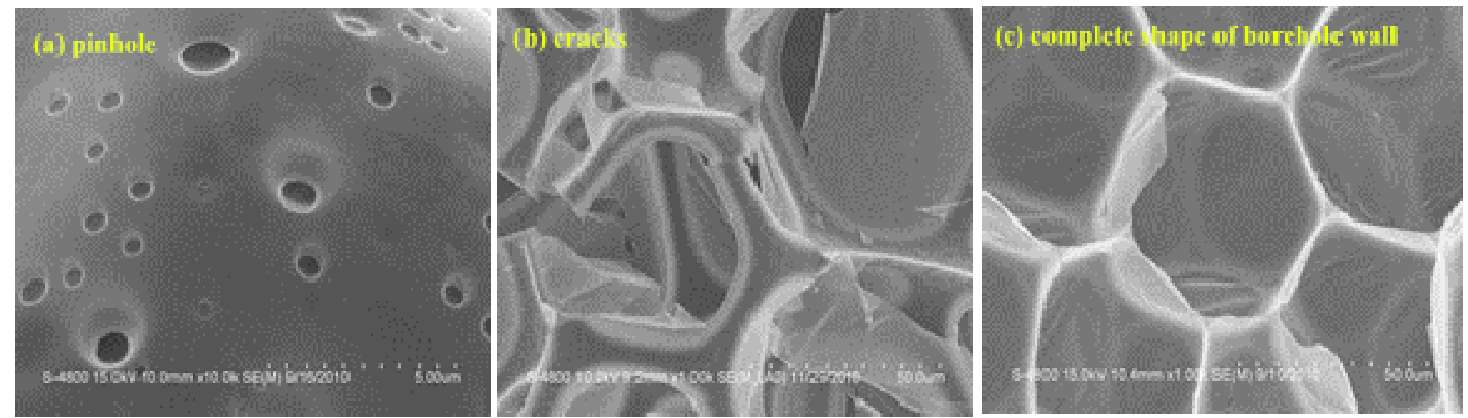

Fig.3 The SEM photograph of different PF foam pore wall structure

\section{The effects of phenolic ratio on phenolic foam microstructure}

Prepared foam board with different phenolic ratio, $n(F) / n(P)$. It was found that reaction activity become higher if $n(F) / n(P)=1.6$ in foaming process, foaming immediately after sulfuric acid was added. If $n(F) / n(P)=1.8$ or 2.0 , heat evolution rate became slower with reaction activity decreasing, made into foam board. But it foamed easily because of a rapid exothermal reaction. As shown in Fig.4, If $\mathrm{n}(\mathrm{F}) / \mathrm{n}(\mathrm{P})=1.6$ or 1.8 , the average pore diameter were more than $100 \mu \mathrm{m}$, as shown in Table 4 . The average pore diameter were $85.32 \mu \mathrm{m}$. If $\mathrm{n}(\mathrm{F}) / \mathrm{n}(\mathrm{P})=2.0$, which was far less than $\mathrm{n}(\mathrm{F}) / \mathrm{n}(\mathrm{P})=1.6$ or 1.8 . On the one hand, slower reaction activity caused heat evolution rate decreased, smooth foaming, shorter gel time was beneficial to cure rapidly, forming small pore size foam. On the other hand, there were some cracks and pinhole on the pore walls with different $n(F) / n(P)$. Comparatively speaking, there were more pinholes for a high water content, but fast curing rate, smooth heat output and less cracks.
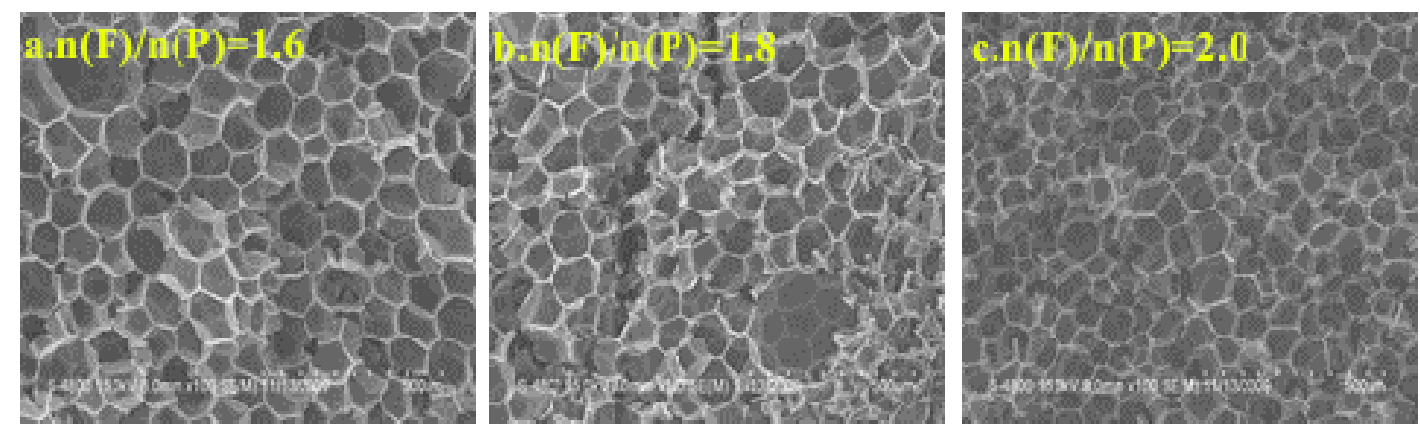

Fig.4 The SEM photograph of different PF foam

Table 4 The microstructure of different $n(F) / n(P)$ of the foam

\begin{tabular}{ccc}
\hline$n(\mathrm{~F}) / n(\mathrm{P})$ & Average Pore Diameter $/ \mu \mathrm{m}$ & Pore Wall Situation \\
\hline 1.6 & 110.93 & Few pinhole and cracks \\
1.8 & 101.11 & Few pinhole and cracks \\
2.0 & 85.32 & More pinhole, few cracks \\
\hline
\end{tabular}

\section{Conclusion}

a)The oxygen index of modified PF foam did raise to 32 , with a low smoke density grade, met the requirements of the $\mathrm{B} 1$ level of combustion performance completely.

b) MMT not only improved the thermal stability of the PF, but also played a thermal insulation, fire-retardant and enhanced role to some extent.

c) PEG and PF formed the complexes, toughening PF.

d) The higher $n(F) / n(P)$ value is, the slower reaction activity will be, forming smaller pore size foam. 


\section{References}

[1] Yinan Zhang. The production and application of phenolic foam board[J]. Liaoning building materials. 2009, 12(2): 25-26.

[2] Jintang Zhou,Zhengjun Yao,Yongxin Chen,Dongbo Wei,Yibing Wu. Thermomechanical analyses of phenolic foam reinforced with glass fiber mat[J]. Materials and Design,2013,51:

[3] Chung-jen Tseng,Kuang-te Kuo. Thermal radiative properties of phenolic foam insulation[J]. Journal of Quantitative Spectroscopy and Radiative Transfer,2001,724:.

[4] Jongmin Kim,Jae-Hyug Lee,Tae-Ho Song. Vacuum insulation properties of phenolic foam[J]. International Journal of Heat and Mass Transfer,2012,5519-20:.

[5] Hongbin Shen,Steven Nutt. Mechanical characterization of short fiber reinforced phenolic foam[J]. Composites Part A,2003,349:.

[6]Haixia Yuan,Weiyi Xing,Hongyu Yang,Lei Song,Yuan Hu,Guan Heng Yeoh. Mechanical and thermal properties of phenolic/glass fiber foam modified with phosphorus - containing polyurethane prepolymer[J]. Polym. Int.,2012,622:. 